\title{
Bio-optical modeling of primary production: consequences of variability in quantum yield and specific absorption
}

\author{
Heidi M. Sosik* \\ Biology Department, MS \#32, Woods Hole Oceanographic Institution, Woods Hole, Massachusetts 02543-1049, USA
}

\begin{abstract}
Much interest is currently focused on attempts to estimate aquatic primary production at a variety of spatial and temporal scales using models which require parameterization of phytoplankton photophysiology. The work described here investigates in situ variability in physiological properties which are important for many bio-optical models of photosynthesis: the maximum photosynthetic quantum yield, the pigment-specific absorption coefficient and the product of the effective functional absorption cross section for photosystem II and the rate limiting turnover time for carbon fixation. Measurements were made on samples collected from 2 depths within the euphotic zone at 29 stations in the California Current System (USA) during the winter to early spring of 1992. Within this region, even during a period of relatively low physical forcing, all 3 parameters were found to be as highly varable as previously documented for a wide range of laboratory culture conditions and natural environments. Significant trends with environmental factors such as light, temperature and nutrient conditions were consistent with previous results from controlled laboratory studies of phytoplankton physiology. The consequences of the observed variability for estimation of primary production were investigated through the use of 2 bio-optical models, one expressed in terms of total phytoplankton absorption and the second accounting for only photosynthetically active absorption. Both models were sensitive to the observed variability in physiology, with greater sensitivity to the achieved photosynthetic quantum yield compared to the specific absorption coefficient. Model estimates were significantly less sensitive to observed variability in the absorption coefficient when only the photosynthetically active absorption was included, but little difference in sensitivity to quantum yield variability was found between the 2 models. Despite the documented mesoscale variability in phytoplankton optical and photosynthetıc properties, model results suggest that it may be reasonable to use constant but representative parameter values for larger or regional scale estimates of primary production.
\end{abstract}

KEY WORDS: Phytoplankton Primary production - Bio-optical modeling P Photosynthetic quantum yield - Light absorption · California Current

\section{INTRODUCTION}

Since it was first possible to measure light in the sea, biological oceanographers have searched for ways to estimate primary production based on light intensity and the abundance of phytoplankton pigments. The history of this search is a long one with many influential participants (e.g. Jenkin 1937, Ryther \& Yentsch 1957, Dubinsky \& Berman 1976, Platt \& Jassby 1976, Morel 1978, 1991, Kiefer \& Mitchell 1983, Eppley et al.

·E-mail: hsosik@whoi.edu
1985, Bidigare et al. 1987, Smith et al. 1987, Platt \& Sathyendranath 1988, Balch et al. 1989, Sakshaug et al. 1989). The reasons for this over half century of perseverance are not difficult to understand given the limitations of other techniques based on laborious incubations. Primary among these limitations are the spatial and temporal scales at which measurements can be made. This was apparent to early workers (e.g. Jenkin 1937, Ryther \& Yentsch 1957), but the contrast in accessible scales between incubation and optical modeling techniques has grown only wider. The introduction of bio-optical sensors which can be deploped on moorings, profiling packages, and satellites has 
expanded the accessible vertical, horizontal, and temporal scales by orders of magnitude (Dickey 1988, Bidigare et al. 1992).

There are different but probably equally important limitations in the application of bio-optical techniques for estimating primary production. To varying degrees of complexity, all bio-optical models require some parameterization of phytoplankton photophysiology. Spatial and temporal variability in this physiology is a source of considerable uncertainty. Ryther \& Yentsch (1957) recognized that factors such as light, temperature and species composition affect the properties of the phytoplankton and that accounting for these effects should improve application of simple chlorophyll-light alcrorithms. This idea has been echoed repeatedly by later workers (e.g. Platt \& Jassby 1976. Balch et al. 1989, Platt et al. 1992).

In an effort to address this issue, models have grown in complexity from relatively simple correlations with limited applicability. Environmental variables besides light intensity have been incorporated (Eppley et al. 1985, Balch et al. 1989); efforts have been made to separate parameterization of processes such as light penetration through the water column, light absorption by the phytoplankton, and the photochemistry involved in photosynthesis (Kiefer \& Mitchell 1983, Platt \& Sathyendranath 1988, Sakshaug et al. 1989, Morel 1991); spectrally dependent processes have been identified and spectral dependence has been incorporated (e.g. Bidigare et al. 1987, Sathyendranath et al. 1989 , Morel 1991).

With these developments in model complexity, the need to adequately parameterize the processes involved in light absorption and subsequent carbon fixation by the phytoplankton has become more apparent and results of recent work, in both the laboratory and the natural environment, has emphasized this point. Many bio-optical models require specification of the pigment-specific absorption coefficient for phytoplankton and some combination of parameters which are used to describe variations in photosynthetic quantum yield as a function of irradiance (e.g. Kiefer \& Mitchell 1983, Sakshaug et al. 1989). Laboratory studies have documented variability in these properties as a function of growth conditions such as light intensity, temperature, and nutrient availability (Ley \& Mauzerall 1982, Dubinsky et al. 1986, Morel et al. 1987. Mitchell \& Kiefer 1988, Herzig \& Falkowski 1989, Chalup \& Laws 1990. Sosik \& Mitchell 1991, 1994, Partensky et al. 1993). In addition, evidence of variability for natural assemblages of phytoplankton is mounting (Kolber et al. 1990, Hoepffner \& Sathyendranath 1992, Babin et al. 1993, 1995. Schofield et al. 1993, Bricaud et al. 1995, Sosik \& Mitchell 1995).
The present study was designed to assess a complete suite of model parameters which reflect the light absorption and photosynthetic properties of natural phytoplankton. The area sampled spanned a broad region of the California Current System (USA) and characterization of the hydrographic and chemical environment was an important component of the work. In addition to describing the range and spatial patterns of variability in parameter values, some insights are provided into the sources of variability and its consequences for modeling primary production using biooptical techniques.

\section{MATERIALS AND METHODS}

Sampling. Sampling was conducted on 2 cruises in the California Current System. On a cruise off southern California, stations were occupied over a regular grid within approximately $30^{\circ}$ to $35^{\circ} \mathrm{N}$ and $117^{\circ}$ to $125^{\circ} \mathrm{W}$ between January 28 and February 13, 1992. This work was conducted in collaboration with the California Cooperative Oceanic Fisheries Investigation (CalCOFI cruise 9202) on the RV 'David Starr Jordan' (see Scripps Institution of Oceanography 1992). On the second cruise, as part of the NOAA Fishery Oceanography and Groundfish Ecology program (cruise preFORAGE 9203, RV 'David Starr Jordan' leg), a survey was conducted off northern California from $37^{\circ}$ to $39^{\circ} \mathrm{N}$ and $122^{\circ}$ to $127^{\circ} \mathrm{W}$ between March 14 and April 2, 1992

Detailed sampling on these cruises has been described previously (Scripps Institution of Oceanography 1992, Sosik \& Mitchell 1995). In this paper, results will be presented from 13 and 16 mid-day stations occupied on cruises CalCOFI 9202 and preFORAGE 9203, respectively. At these stations routine hydrographic measurements including temperature, salinity, oxygen and macronutrient concentrations were supplemented by collection of samples for primary productivity incubations from depths throughout the euphotic zone corresponding to fixed fractions of surface irradiance. On CalCOFI 9202, these sample depths were estimated from the Secchi depth, while on preFORAGE, the target depths were determined from profiles of photosynthetically available radiation (PAR, 400 to $700 \mathrm{~nm}$; see below). Samples for primary productivity work were collected after 10:00 h local time and held in cool dark conditions until the start of incubations. Samples collected from all depths were analyzed for chlorophyll a (chl a) and phaeopigment (phaeo) concentrations by standard fluorometric techniques after filtration onto Whatman GF/F filters and extraction in cold $90 \%$ acetone. In addition, particulate absorption and fluo- 
rescence measurements were made on all samples (see below).

Optical profiles: For each of the stations reported here, spectral measurements of in situ irradiance in the top $200 \mathrm{~m}$ were made with a Biospherical Instruments Inc. (San Diego, CA, USA) MER 1012 underwater radiometer (Mitchell \& Holm-Hansen 1991). Seven narrow band $(-10 \mathrm{~nm}$ full width half power) downwelling vector irradiance channels $(410,441,488,520$, 565,633 , and $683 \mathrm{~nm}$ ) were used for characterizing the spectral quality of the underwater light field at the depths sampled for primary productivity assays. Scans of spectral downwelling irradiance were also conducted with the instrument secured on the deck of the ship to characterize the visible light incident at the deck incubators. For these scans, a 'dry' calibration provided by Biospherical Instruments was applied to the data. For one day on preFORAGE 9203 when deck scans were not acquired, the average relative spectrum for the remaining days of the cruise was used in the model application described below. The MER 1012 was also equipped with a downwelling quantum scalar irradiance sensor which was used on preFORAGE 9203 to determine PAR-based optical depths for water sampling. PAR incident on the deck of the ship was measured with a similar sensor (QSR-240; Biospherical Instruments Inc.) and logged at 1 min intervals throughout each of the cruises.

Analysis of particulate optical properties. Particulate absorption: Water samples were filtered onto Whatman GF/F filters for particulate absorption analysis as described previously (Sosik \& Mitchell 1995). Briefly, before and after extraction with methanol, optical density relative to a seawater-saturated blank filter was measured on fresh samples at sea using a Perkin Elmer Lambda 6 dual beam spectrophotometer All spectra were normalized to zero optical density at $750 \mathrm{~nm}$, corrected for pathlength amplification effects using the Quantitative Filter Technique (QFT) of Mitchell (1990), and smoothed using Fourier transform techniques to remove high frequencies $\left(>0.039 \mathrm{~nm}^{-1}\right)$. By difference between absorption before $\left[a_{p}(\lambda)\right]$ and after extraction $\left[a_{d}(\lambda)\right]$, an estimate of the in vivo absorption by methanol-extractable phytoplankton pigments $\left[a_{p h}(\lambda)\right]$ was determined (Kishino et al. 1985). Pigment specific absorption by the phytoplankton $\left[a^{*}{ }_{p h}(\lambda)\right]$ was calculated by normalization to the concentration of chl a plus phaeo (chl + phaeo) since phaeopigments, although detrital, extract readily in methanol and potentially contribute to $a_{p h}(\lambda)$. The inclusion of absorption by phaeopigments in these estimates of phytoplankton absorption is an unavoidable operational limitation of the Kishino et al. (1985) technique.

Photosynthetically active absorption: Chl a fluorescence excitation spectra were used to quantify ab- sorption by phytoplankton pigments which actively contribute to photosynthesis $\left[a_{p s}(\lambda)\right]$ (Sosik \& Mitchell 1995). Similar to the method of Neori et al. (1986. 1988 , whole seawater samples were treated with 3-(3,4-dichlorophenyl)-1,1-dimethlyurea (DCMU) and excitation spectra from 300 to $700 \mathrm{~nm}$ (5 nm slit) were measured in $1 \mathrm{~cm}$ cuvettes with a Spex Industries Fluoromax spectrofluorometer and with emission monitored at $730 \mathrm{~nm}$ (20 nm slit). The spectrofluorometer was equipped with a red sensitive photomultiplier and a stirring accessory and a Schott glass long pass filter (RG715) was mounted between the sample and the detector to block stray excitation light. Spectra were quantum corrected as described in Sosik \& Mitchell (1995), filtered seawater blanks were subtracted, and final spectra were smoothed with a median filter, followed by the same high frequency filter applied to the absorption spectra. As detailed elsewhere (Sosik \& Mitchell 1995), the final fluorescence spectra $\left[F_{\mathrm{DCMU}}(\lambda)\right]$ were used as a proxy for $a_{\mathrm{ps}}(\lambda)$

$$
a_{p s}(\lambda)=F_{\text {DCMU }}(\lambda) \cdot \frac{a_{p s}(675)}{F_{\text {DCMU }}(675)}
$$

where

$$
a_{p s}(675)=a_{p h}(675)-a_{\text {phdeo }}^{*}(675) \cdot \text { phaeo }
$$

and $a_{\text {phaeo }}^{*}(675)=0.008 \mathrm{~m}^{2}(\mathrm{mg} \text { phaeo })^{-1}$ with all wavelengths given in $\mathrm{nm}$. Pigment-specific coefficients, a phaed $(\lambda)$, were determined by normalization to the concentration of chl a.

Similar approaches to estimating photosynthetically active absorption have been previously proposed (Sakshaug et al. 1991, Johnsen \& Sakshaug 1993) for work with mono-specific cultures of phytoplankton. The method introduced here includes a correction for red absorption by phaeopigments which may be significant in natural samples. Despite this correction, there may still be substantial uncertainty in the choice of scaling factor for the $F_{\mathrm{DCMu}}(\lambda)$ values, due to factors such as the distribution of chl a and accessory pigments in the light harvesting antennas of photosystem (PS) I and PS II, variations in energy transfer efficiency to PS II at the scaling wavelength, and energy spillover between PS Il and PS I. For lack of precise information about these factors, the simplest approach (i.e. assuming 100\% transfer efficiency for chl a and equal spectral distribution of energy across PS I and PS II has been implemented here. Johnsen \& Sakshaug (1993), working with dinoflagellates, proposed that use of $85 \%$ transfer efficiency at $676 \mathrm{~nm}$ may reflect a more accurate assessment of PS II absorption. The choice of this factor will influence estimates of the magnitude of the quantum yield for photosynthesis based on active absorption see des- 
cription of $\phi_{\max \text { ps }}$ below), essentially by virtue of the definition of active absorption. Despite this uncertainty, however, internally consistent estimates of photosynthetic rate (as derived in the modeling described below) can be obtained with any set of assumptions concerning the active absorption.

Primary productivity. Photosynthesis-irradiance curves: Near surface samples ( 94\% surface irradiance) and samples from the depth where irradiance was attenuated to $-4.5 \%$ of surface were incubated at 20 different irradiances ranging from 5 to $400 \mu \mathrm{mol}$ quanta $\mathrm{m}^{-2} \mathrm{~s}^{-1}$ to determine photosynthesis-irradiance $(P-I)$ curves. The light source consisted of a tungstenhalogen lamp with a piece of BG-14 Schott glass mounted between the lamp and the samples to modify the spectrum to simulate typical underwater quality. The resulting quantum-based spectrum incident on the samples had a peak at $522 \mathrm{~nm}$ with output reduced to half within $\pm 70 \mathrm{~nm}$ of the peak. The absolute magnitude of PAR incident inside the sample containers was measured with a QSL-100 quantum scalar irradiance meter calibrated for this blue-green spectrum (Biospherical Instruments Inc.) and the magnitude as a function of wavelength was then determined by normalizing the integral from 400 to $700 \mathrm{~nm}$ of the relative quantum spectrum to match the measured PAR.

$\mathrm{NaH}^{14} \mathrm{CO}_{3}$ was added to water samples ( 1 to $2 \mu \mathrm{Ci}$ $\mathrm{ml}^{-1}$ final concentration) and 5 or $8 \mathrm{ml}$ subsamples were incubated in $20 \mathrm{ml}$ borosilicate scintillation vials in a modified 'photosynthetron' (Lewis \& Smith 1983) for $1 \mathrm{~h}$ beginning within $1 \mathrm{~h}$ of local apparent noon. The incubator was adjusted to ambient temperatures using a circulating water bath and incubations were stopped by immediate addition of concentrated $\mathrm{HCl}$ directly to the sample vials. Acidified samples were mechanically shaken for several hours before addition of scintillation fluid. Radioactive disintegration rates were determined using a Beckman LS 1801 liquid scintillation counter and quench correction. Uptake was determined after subtraction of 'time zero' samples (average of triplicates) which were acidified immediately at the start of the incubation period.

The resulting $P-I$ data were fit to the following model:

$$
P=\phi_{\max , p h} \frac{1-\mathrm{e}^{-\sigma \tau \int E(\lambda) \mathrm{d} \lambda}}{\sigma \tau \int E(\lambda) \mathrm{d} \lambda}(\operatorname{chl}+\text { phaeo }) \int a_{\mathrm{ph}}(\lambda) E(\lambda) \mathrm{d} \lambda
$$

(3; Model 1)

where $P$ is the rate of primary production, $\phi_{\max , p h}$ is the maximum photosynthetic quantum yield, $\sigma \tau$ is the product of the apparent PS II functional absorption. cross-section and the rate limiting turnover time for carbon fixation, and $E(\lambda)$ is scalar irradiance. All inte- grals were performed for wavelengths from 400 to $700 \mathrm{~nm}$. This is a spectral variation of the model used by Sakshaug et al. (1989) to represent steady state growth in laboratory cultures. As for $a^{*}{ }_{p h}(\lambda), \sigma$ is a wavelength-dependent quantity, but this spectral dependence cannot be independently determined from broadband $P-I$ and whole cell absorption data. For this reason, the product $\sigma \tau$ derived from these measurements is a weighted spectral average which is exactly relevant only for the spectral light quality of the $P$-I incubator. This may also be true for $\phi_{\max \text {.ph }}$ since spectral dependence of this parameter has been reported (Bidigare et al. 1989, Schofield et al. 1990, 1991). To the extent that the spectral quality of interest is similar to the blue incubator light (as in modeling production based on typical underwater irradiance) this problem is minimized. Without the wavelength-dependent integrals, Eq. (3) is actually mathematically identical to the model proposed by Webb et al. (1974) and was chosen over other P-I models because it represents the data well and since, as presented, the parameters can be assigned mechanistic interpretations which are supported by many years of kinetic studies of photosynthesis, albeit at shorter time scales than employed in this work (see discussion in Cullen 1990). For the range of irradiances examined, photoinhibition was not observed and so was not incorporated. Best fits, asymptotic standard errors, and confidence intervals for the model parameters were determined using the nonlinear regression module of the software SYSTAT (SYSTAT, Inc., Evanston, IL, USA). Representation of the P-I data by this model was excellent with $84 \%$ of the solutions giving $r^{2}$ values $\geq 0.99$ and with only 1 case as low as 0.93. Light saturated rates of photosynthesis ranged from 1.5 to 7.5 and 1.1 to $5.1 \mathrm{mg} \mathrm{C}(\mathrm{mg} \mathrm{chl} \mathrm{a})^{-1}$ $\mathrm{h}^{-1}$ on the CalCOFI and preFORAGE cruises, respectively and are consistent with other observations for this region (Prézelin et al. 1987, Hood et al. 1991 , Schofield et al. 1993).

In addition to Model 1, parameter values were also determined for a related model formulated in terms of only the photosynthetically active absorption by the phytoplankton where, as proposed by Sosik \& Mitchell (1995),

$$
P=\phi_{\max , \mathrm{ps}} \frac{1-\mathrm{e}^{-\sigma \tau \int E(\lambda) \mathrm{d} \lambda}}{\sigma \tau \int E(\lambda) \mathrm{d} \lambda}(\operatorname{chl} \alpha) \int \alpha_{\mathrm{ps}}^{*}(\lambda) E(\lambda) \mathrm{d} \lambda
$$

(4; Model 2)

In this case, $a_{p h}^{*}(\lambda)$ is replaced by $a^{*}{ }_{p s}(\lambda)$ and the relevant quantum yield becomes $\phi_{\text {max.ps }}$. The parameter $\phi_{\max , p s}$ differs from $\phi_{\max , p h}$ in that it represents the amount of carbon fied for each mole of photosynthetically active photons absorbed rather than total photons absorbed by the phytoplankton. 


\section{RESULTS AND DISCUSSION}

\section{General hydrography}

Sampling on these cruises covered a wide range of oceanographic conditions. The survey areas span a variety of coastal environments, as well as open ocean conditions more typical of the central North Pacific. General differences in water masses are delineated by the main jet of the California Current. On CalCOFI 9202 the main current meandered through the offshore water of the region sampled, while on preFORAGE 9203 it bisected the survey area (Figs. 1A \& 2A). Both cruises were conducted during an El Niño event which, as described by Hayward (1993), was manifest in California coastal waters by anomalously high sea level and sea surface temperatures, along with an unusually broad surface countercurrent near the coast (see Figs. 1A \& 2A). Phytoplankton biomass, macrozooplankton biomass, and primary production were also relatively low (Hayward 1993). In general, the level of physical forcing throughout the region was low during the sampling period.

On CalCOFI 9202, surface temperatures ranged from 13 to $16^{\circ} \mathrm{C}$ and were highest in the southorn offshore region of the grid area, as well as in the Southern California Bight (Fig. 1B); these waters generally had the lowest surface chl a concentrations (as low as $0.07 \mathrm{mg} \mathrm{m}^{-3}$ ), but values only rarely exceeded $1 \mathrm{mg}$ $\mathrm{m}^{-3}$ in the entire area sampled (Scripps Institution of Oceanography 1992, Sosik \& Mitchell 1995). Off northern California approximately 1 mo later (preFORAGE
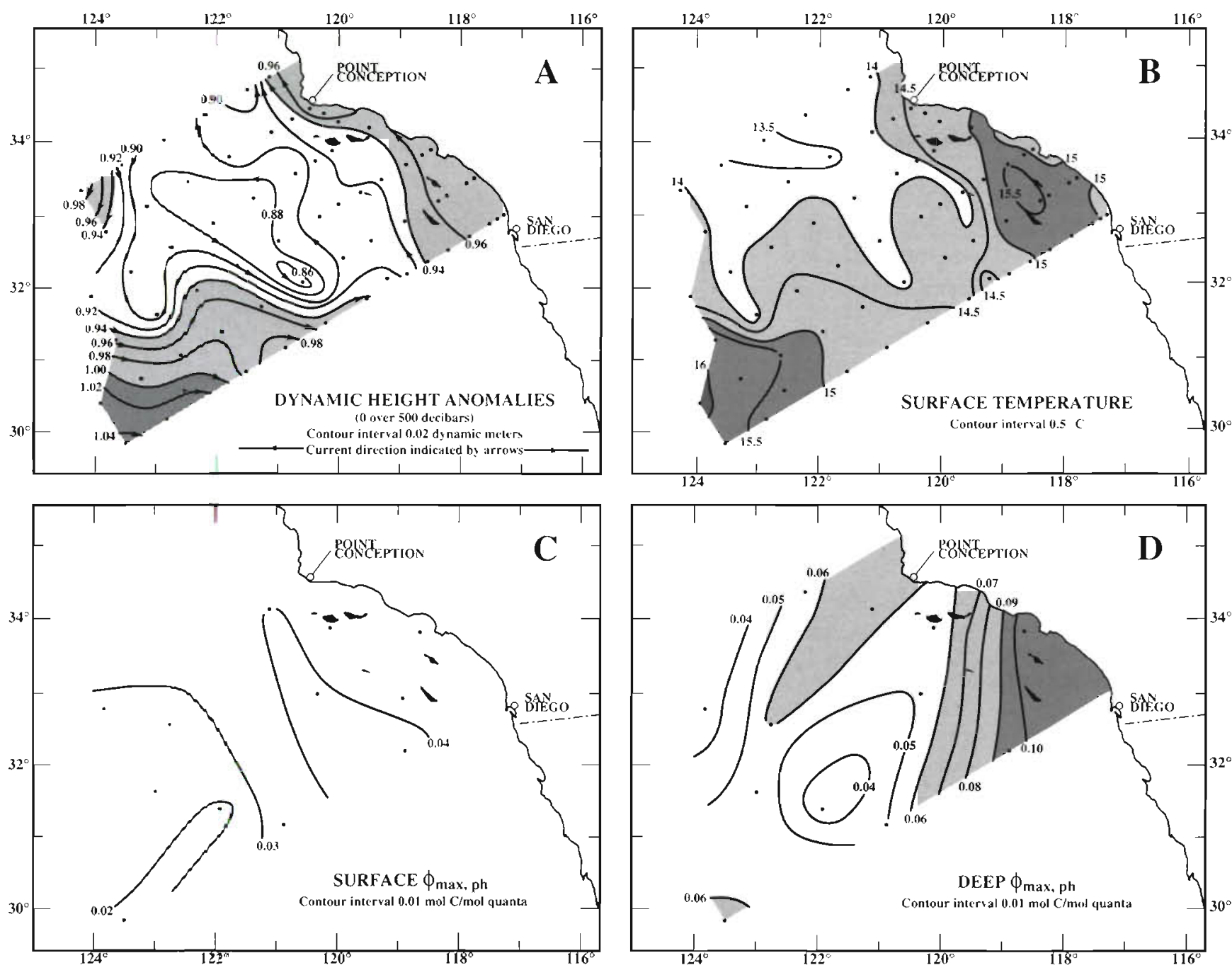

Fig. 1. Contour maps showing current structure and distributions of properties off southern California (USA) in January-February 1992 (CalCOF1 9202). (A) Surface dynamic height anomalies relative to $500 \mathrm{db}$; (B) surface temperature; (C) $\phi_{\mathrm{max} \text {. ph }}$ for samples collected from the near surface; and (D) $\phi_{\text {max.ph }}$ for samples collected from the depth where PAR was attenuated to $\sim 4.5 \%$ of 

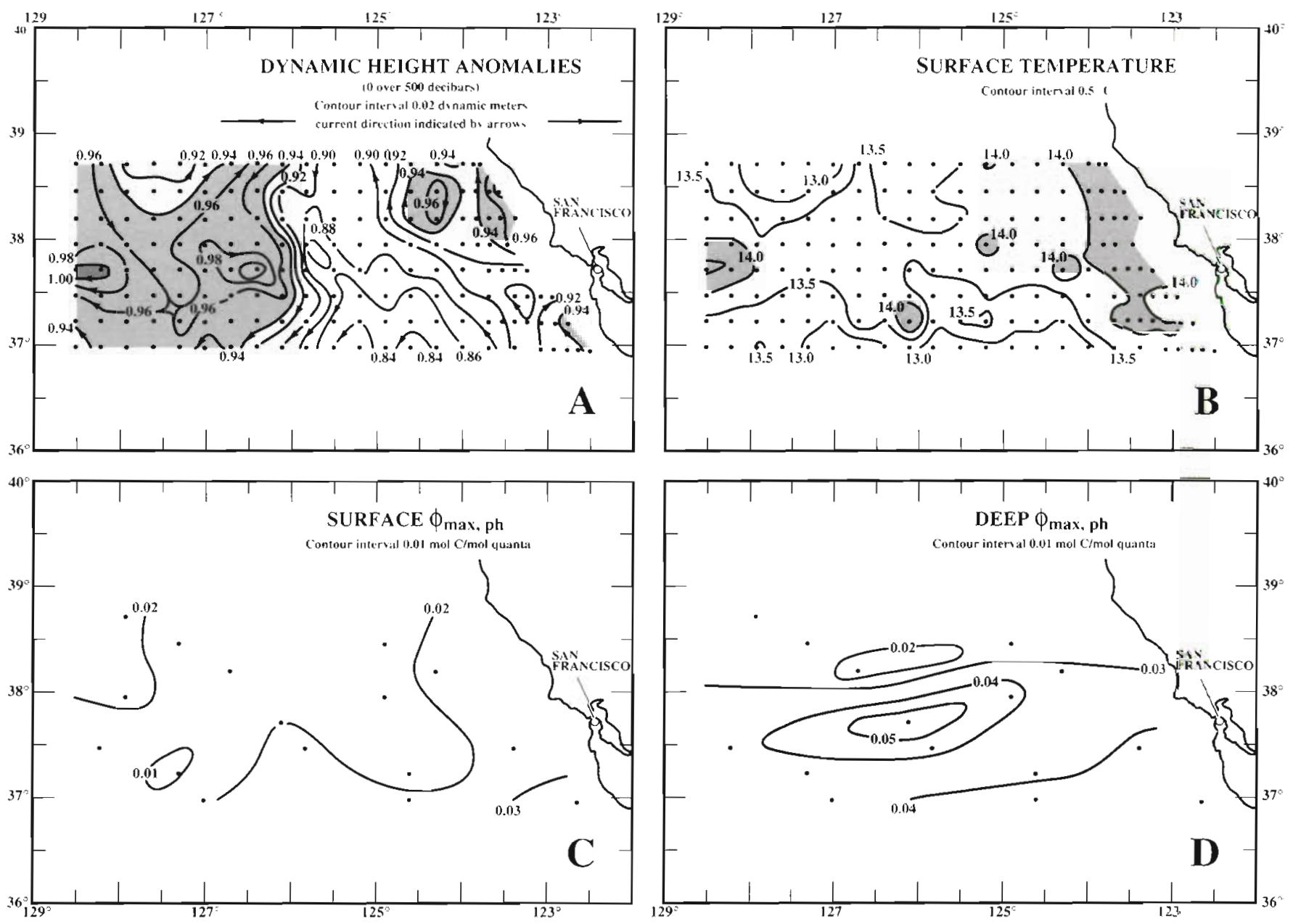

Fig. 2. Contour maps as in Fig. 1, but for northern California (preFORAGE 9203) during March-April 1992

9203), surface temperatures were somewhat cooler $(12$ to $15^{\circ} \mathrm{C}$ ), the range for chl a concentration was similar. and spatial patterns were weaker (see Fig $2 \mathrm{~B}$ for temperature)

\section{Variability in specific absorption}

Details of variability in $a^{*},(\lambda)$ and $a^{*}{ }_{p s}(\lambda)$ observed on these cruises have been previously described (Sosik \& Mitchell 1995). For the subset of samples used in this study (i.e. mid-day stations, near surface and $4.5 \%$ of surface PAR), the general trends are similar to those reported for the whole dataset. Values at the blue absorption peak ranged from 0.024 to $0.089 \mathrm{~m}^{2}$ (mg chl + phaeo) $)^{-1}$ for $a_{j h}^{\cdot}(440)$ and between 0.023 and $0.059 \mathrm{~m}^{2}$ (mg chlj ' for $\mathrm{a}^{\text {: }}(440)$; surface values were generally higher than those for the deeper samples and only small differences were observed between cruise means for $a^{*}{ }_{p s}(\lambda)$, with slightly larger differences between cruises for $a^{*}{ }_{p h}(\lambda)$ (Table 1).
Variability in $\phi_{\max , p h}, \phi_{\max , p s}$ and $\sigma \tau$

$\phi_{\max , p h}$

The observed values of $\phi_{m a x \text { ph }}$ varied by a factor of 10 , ranging from less than $10 \%$ to nearly $85 \%$ of the theoretical maximum of $0.125 \mathrm{~mol} \mathrm{C}$ (mol quanta $)^{-1}$, and spatial patterns were evident in the distribution of values. On both cruises, $\phi_{\text {max }}$ for the near surface samples was generally lower and less variable than the samples collected from greater depths (Figs. 1C, D \& $2 \mathrm{C}, \mathrm{D}$; Table 1). While discernible spatial patterns are necessarily coarse given the sampling resolution, horizontal patterns were evident particularly for the deeper samples. Off southern California, values of $\rho_{\text {max.ph }}$ approaching the theoretical maximum were found for deep samples in the Southern California Bight, with more moderate values over the rest of the sample area (Fig. 1D). Off northern California, isolines of $\phi_{\text {max.ph }}$ were generally oriented latitudinally (Fig. 2C,D). In contrast to the previous cruise, the highest values 
observed were only half of the theoretical maximum and values as low as typically found near the surface were observed for deep samples in the northernmost area (Fig. 2D).

The range of variability in quantum yield observed in this study is generally as large as has been reported previously for phytoplankton cultures and natural assemblages. This is true for phytoplankton grown under a wide range of light, nutrient and temperature conditions in the laboratory (Falkowski et al. 1985, Morel et al. 1987, Herzig \& Falkowski 1989, Chalup \& Laws 1990. Schofield et al. 1990, Sosik \& Mitchell 1991, 1994, Partensky et al. 1993). In the present study $\phi_{\max , p h}$ approached the theoretical maximum for deep samples on CalCOFI 9202 , while many other observations were much lower than the value of $0.06 \mathrm{~mol} \mathrm{C}$ (mol quanta) ${ }^{-1}$ which was found to describe a variety of steady-state growth conditions by Kiefer \& Mitchell (1983). The level of variability is similar to that reported previously for waters of the Southern California Bight by Schofield et al. (1991, 1993) and the Gulf of St. Lawrence, Canada (Babin et al. 1995), although, with the exception of one observation in the Gulf of St. Lawrence, the values of $\phi_{\text {max.ph }}$ found in these studies were consistently less than half of the theoretical maximum. Values as high as $0.10 \mathrm{~mol} \mathrm{C} \mathrm{(mol} \mathrm{quanta)}{ }^{-1}$ have been reported for a site in the Sargasso Sea (Cleveland et al. 1989) and in situ quantum yields near this value have also been reported for deep samples in Japanese coastal waters (Kishino et al. 1986), in the eastern North Pacific including the California Current (Mitchell 1987), and in the northern North Atlantic (Carder et al. 1995). Quantitative comparisons between studies must be interpreted cautiously, however, since different $P$ - $I$ models result in different estimates of the initial slope (Bidigare et al. 1992, Frenette et al. 1993) and thus $\phi_{\max , \mathrm{ph}}$.

$$
\phi_{\max , p s}
$$

Application of Model 2 (Eq. 4) results in values of $\phi_{\max , p s}$ which are consistently higher than $\phi_{\max , p h}$ (an average of $62 \%$ higher). This result is expected since $a_{\text {ps }} \cdot(\lambda)$ does not include absorption by photoprotective pigments. These pigments do not transfer excitation energy to the photochemical reaction centers and thus lower the achieved maximum quantum yield $\left(\phi_{\max }\right.$ ph $)$. Based on pigment reconstruction techniques (Bidigare et al. 1990) for estimation of $a^{*}{ }_{p h}(\lambda)$ and $a^{*}{ }_{p s}(\lambda)$, similarly higher values of $\phi_{\max \text { ps }}$ relative to $\phi_{\text {max,ph }}$ have been reported for laboratory cultures (Bidigare et al. 1989) and for field measurements (Bidigare el al. 1992). Consistent with the results reported by Bidigare et al. (1992), we observed little change in the spatial patterns between $\phi_{\max , p h}$ and $\phi_{\max , p s}$ or in the level of variability (Fig. 3). Despite lower variability in $\alpha^{*}{ }_{p s}(\lambda)$ relative to $a^{*}{ }_{\mathrm{ph}}(\lambda)$ (Sosik \& Mitchell 1995), $\phi_{\max , \mathrm{ps}}$ remains highly variable. For the region where the highest values of $\phi_{\max , p h}$ were observed, 2 estimates of $\phi_{\max , \mathrm{ps}}$ actually exceed the theoretical maximum by as much as $22 \%$. When statistical uncertainty associated with the regression to Eq. (4) is considered, however, only 1 of these estimates has a $95 \%$ confidence interval which does not include $0.125 \mathrm{~mol} \mathrm{C}$ (mol quanta) $)^{-1}$. Other uncertainties associated with the estimation of quantum yield, such as the accuracy of the particulate absorption measurements (see Mitchell 1990), are enough to account for the remaining discrepancy.

This observation of high variability in $\phi_{\max , \mathrm{ps}}$ is of significance for providing some insight into the sources of natural variability at the level of mechanisms acting within the phytoplankton cells. If changes in the relative abundance of photoprotective accessory pigments compared to photosynthetically active pigments are an important source of variability in $\phi_{\text {max,ph }}$, then $\phi_{\max \text { ps }}$ should show markedly less variability. Since this has not been observed, we can infer that, although this is important for variability in specific absorption, it is a relatively minor factor in determining the magnitude of $\phi_{\max , \mathrm{ph}}$. Other potential sources of variability such as 

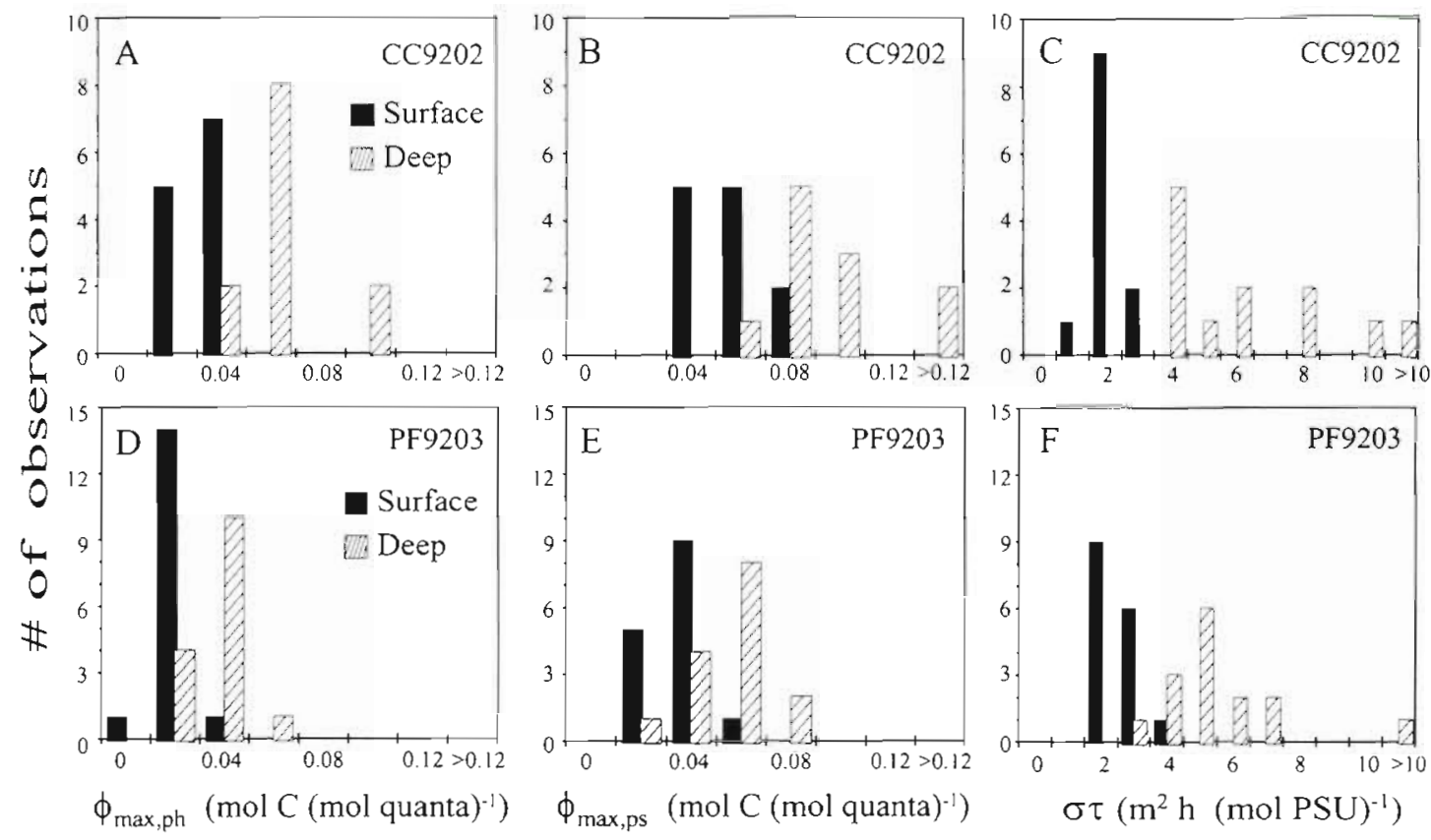

Fig. 3. Frequency distributions of observed optical and photosynthetic properties for samples collected at 2 depths from stations off northern (preFORAGE 9203) and southern California (CalCOFI 9202). 'Deep' indicates samples collected from the depth where surface PAR was attenuated to $4.5 \%$. (A) $\phi_{\max , p h}$ for CalCOFI 9202; (B) $\phi_{\text {max.ph }}$ for preFORAGE 9203; (C) $\phi_{\max , p s}$ for CaICOFI 9202; (D) $\phi_{\text {max,ps }}$ for preFORAGE 9203; (E) $\sigma \tau$ for CalCOFI 9202; and (F) $\sigma \tau$ for preFORAGE 9203

changes in the overall efficiency of energy transfer to the reaction centers must be driving the observed variability and should be further explored for natural assemblages of phytoplankton. Better constraint of the magnitude of $a^{\circ}{ }_{p s}(\lambda)$, than can be obtained with the relatively simple assumptions used here (see 'Materials and methods'), may lead to reduced variability in estimates of $\phi_{\text {max.ps. }}$.

$\sigma \tau$

While values of the product $\sigma \tau$ have rarely been reported for natural assemblages of phytoplankton, this parameter is equivalent to the inverse of the light intensity required to saturate photosynthesis $\left(I_{k}\right)$, often derived from $P$-I curves. Field applications of pumpand-probe type fluorometry have provided the few independent estimates of $\sigma$ and $\tau$ currently available for natural phytoplankton (Kolber et al. 1990, Falkowski 1992). The observations described here show that, as for the other phytoplankton properties, the product $\sigma \tau$ was highly variable ranging from 1.2 to $>10 \mathrm{~m}^{2} \mathrm{~h}(\mathrm{~mol} \mathrm{PSU})^{-1}$. In contrast to the comparison between cruises for $\phi_{\max \text {,ph }}$ and $\phi_{\max , p s}$ there was no apparent difference in $\sigma \tau$ values between southern and northern California waters (Table 1). There was, however, a striking difference between surface and deep samples; surface values were relatively constant near $2 \mathrm{~m}^{2} \mathrm{~h}(\mathrm{~mol} \text { PSU) })^{-1}$ and deep values were higher and much more variable (Fig. 3E, F; Table 1). These results are consistent with previous reports for $I_{k}$ which describe high variability and which attribute the lower values often found for phytoplankton sampled from greater depths to photoacclimation (e.g. Ryther \& Menzel 1959, Harrison \& Platt 1986. Schofield et al. 1993). The observations also compare favorably with those from the laboratory when both $\sigma$ and $\tau$ have been estimated based on rapid ( $\mu$ s-scale) photosynthetic response; for a range of species and growth conditions, Dubinsky et al. (1986) found $\sigma \tau$ values varying from 0.8 to $6.0 \mathrm{~m}^{2} \mathrm{~h}$ (mol PS II) ${ }^{-1}$, with generally higher values for cells grown at low irradiances. Almost all the values observed in the present study, however, are higher than the composite value of $1.2 \mathrm{~m}^{2} \mathrm{~h}$ (mol PSU) ${ }^{-1}$ found to describe adequately a range of steady-state growth conditions in diatom cultures (Sakshaug et al. 1989).

\section{Sources of variability}

Studies conducted under controlled conditions in the laboratory, as well as some recent field evidence, suggest that environmental conditions such as light, temperature and nutrient availability can have large effects on the photophysiology of phytoplankton. Quantum yield has been shown to be generally lower under high irradiances (Dubinsky et al. 1986, Chalup \& 
Laws 1990); both steady state nutrient limitation and nutrient stress in batch culture tend to lower quantum yields (Welschmeyer \& Lorenzen 1981, Cleveland \& Perry 1987, Chalup \& Laws 1990, Sosik \& Mitchell 1991); and low temperatures similarly result in reduced quantum yield (Levasseur et al. 1990, Sosik \& Mitchell 1994). Laboratory measurements of photosynthetic cross-sections and turnover times also demonstrate variability induced by irradiance (Myers \& Graham 1971, Falkowski et al. 1981, Ley \& Mauzerall 1982, Dubinsky et al. 1986) and nutrients (Kolber et al. 1988, Herzig \& Falkowski 1989, Greene et al. 1991); generally lower values of $\sigma \tau$ have been found under high light and nutrient-replete conditions. For natural phytoplankton assemblages, Cleveland et al. (1989), sampling at a station in the Sargasso Sea, documented an increase in maximum quantum yield with proximity of sample depth to the nitracline and Kolber et al. (1990), working in the Gulf of Maine (USA), found variability in the quantum yield of chlorophyll fluorescence and in absorption cross-sections for PS II which supports a role for regulation by nutrient availability.

In a field study such as this one, covariance of environmental factors makes it difficult to separate the effects of different environmental variables and it is not possible to explain the variability observed in phytoplankton properties based on any single factor. Trends in the overall data set, however, are consistent with potential sources of variability expected based on results from laboratory studies. For both study areas, $\phi_{\max . p h} \phi_{\max . p s}$ and $\sigma \tau$ tended to be lower for the surface samples where light was higher and macronutrients were less abundant (Table 1). Although differences in temperature were large at some stations, average temperatures were very similar between surface and the $4.5 \%$ light level making generalizations regarding this variable difficult. Between the cruises, average phytoplankton parameter values tended to be lower on preFORAGE 9203 which is consistent with somewhat lower average temperatures and $\mathrm{NO}_{3}{ }^{-}$concentrations (Table 1 ).

These data suggest that variability in $\phi_{\text {max.ph }}$ is well correlated with changes in hydrographic and chemical structure. This observation is in contrast to the results obtained by Schofield et al. (1993) for a study with higher spatial resolution and covering a smaller area of the Southern California Bight. These authors performed multiple linear regression analysis for $\phi_{\max , p h}$ against a variety of environmental parameters and found none of them to be significant predictors of $\phi_{\max . p h}$, and overall only $12 \%$ of the variance in $\phi_{\max , p h}$ could be explained. A similar analysis on the present data set yields a different result. Optical depth for PAR, temperature, distance above the nitracline (depths below indicated with values $<0$ ), distance above the pycnocline, and $\mathrm{NO}_{3}$ concentration were used as the pool of independent variables for input Although the required assumptions (i.e. normal distributions and random errors) are not strictly met for all variables involved, a backward stepwise multiple linear regression analysis was conducted as a first order indication of whether a significant amount of variance can be explained. The analysis was performed and approximate probabilities determined using the regression routines available in the software package SYSTAT (SYSTAT, Inc.).

Although there is no mechanistic justification for a linear combination of environmental variables as predictors for these physiological parameters, a high level of the variance in $\phi_{\max , \text { ph }}, \phi_{\max , p s}$ and $\sigma \tau$ can be explained by combinations of the environmental inputs. Optical depth, temperature and distance above the nitracline together explain 59 and $65 \%$ of the variance in $\phi_{\max , p h}$ and $\phi_{\text {max,ps }}$ respectively (Table 2 ). For $\sigma \tau$, distance above the nitracline is replaced as a significant predictor by $\mathrm{NO}_{3}{ }^{-}$concentration, while optical depth and temperature remain important. A total of $84 \%$ of the variance in $\sigma \tau$ can be explained (Table 2), with $61 \%$ due to optical depth alone. As discussed above, the directions of the correlations with light, temperature, and nutrient availability are consistent with published results from controlled laboratory studies where these factors can be easily separated. Generally these results are consistent with other recent evidence that points to the importance of factors other than light availability in regulating variability in the optical and photosynthetic properties of natural phytoplankton assemblages (Cleveland et al 1989, Kolber et al. 1990, Platt et al. 1992).

Table 2. Results of backward stepwise multiple linear regression analysis for $\phi_{\text {max } x \text {,h, }} \phi_{\text {max,ys }}$ and $\sigma \tau$ observations pooled for all depths and both cruises. Input predictors were temperature, optical depth for PAR, $\mathrm{NO}_{3}{ }^{-}$concentration, distance above the nitracline, and distance above the pycnocline. Significant variables at the 0.05 level are indicated, with + and - indicating direction of the partial correlations. Amount of variance explained by the final regression and the overall probability are also given

\begin{tabular}{|c|c|c|c|c|}
\hline $\begin{array}{l}\text { Dependent } \\
\text { variable }\end{array}$ & Significant predictors & $N$ & $r^{2}$ & Overall p \\
\hline$\phi_{\text {mllax,ph }}$ & $\begin{array}{l}\text { + Optical depth, } \mathrm{p}<0.001 \\
\text { + Temperature, } \mathrm{p}<0.001 \\
\text { - Dist. above nitracline, } \mathrm{p}<0.03\end{array}$ & 53 & 0.59 & $<0.0001$ \\
\hline$\Phi_{\operatorname{maxps}}$ & $\begin{array}{l}\text { +Optical depth, } \mathrm{p}<0.001 \\
\text { + Temperature, } \mathrm{p}<0.001 \\
\text { - Dist. above nitracline, } \mathrm{p}<0.05\end{array}$ & 51 & 0.65 & $<0.0001$ \\
\hline$\sigma \tau$ & $\begin{array}{l}\text { +Optical depth, } \mathrm{p}<0.001 \\
+\mathrm{NO}_{3}^{-}, \mathrm{p}<0.001 \\
\text { - Temperature, } \mathrm{p}<0.02\end{array}$ & 53 & 0.84 & $<0.0001$ \\
\hline
\end{tabular}


These results bode well for our ability to predict physiological parameters based on more readily available measurements, at least at the spatial scale examined here. It is particularly encouraging that this was found under conditions with a high level of variability in physiological properties and relatively low physical forcing for the California Current System. A possible source of the disparity between these results and those of Schofield et al. (1993) is related to the issue of spatial scales of variability. Although sample sizes are similar and their sample area spanned similar hydrographic conditions, their sampling occurred more intensively over a much smaller area. Due to the number and complexity of potentially important factors, the ability to explain environmentally induced variability in phytoplankton physiological properties may depend strongly on the spatial scale examined. In addition, the present study differs from that of Schofield et al. (1993) in that it considers only noon time measurements of photosynthetic properties, thereby eliminating the documented diel changes as a source of variation (Harding et al. 1982, Prézelin et al. 1987, Cullen et al. 1992). Evaluation of the significance of this difference will require better characterization of the relative importance of different temporal scales of variability for natural phytoplankton assemblages.
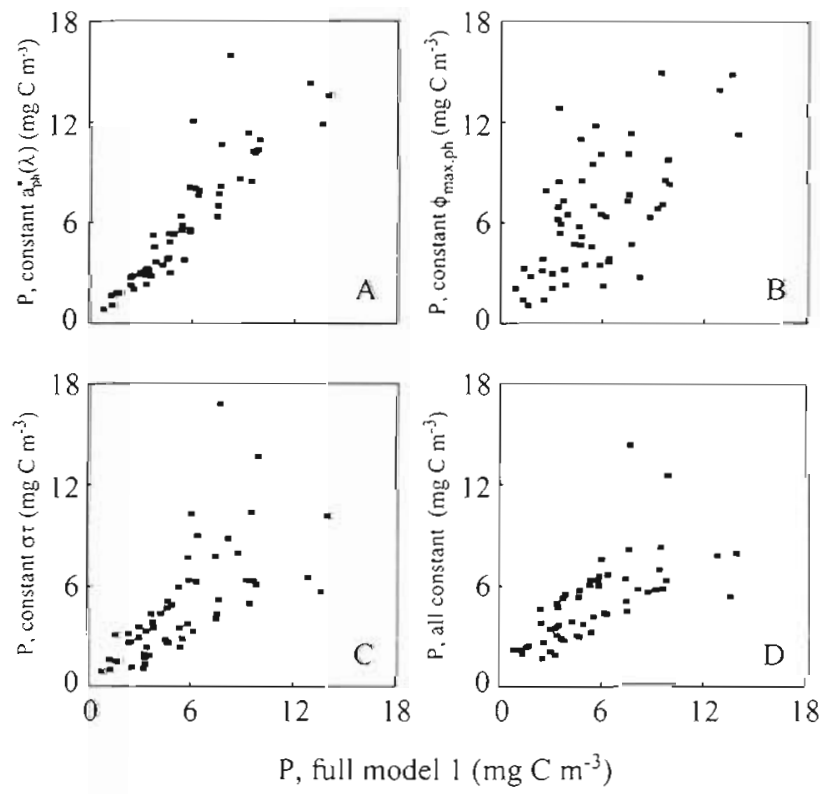

Fig. 4. Scatterplots of modeled primary production comparing estimates when parameters are held constant at the mean values for all observations, with estimates using 'full' measured variability in all parameters (see text for details). All calculations were with Model 1 (Eq. 3) which is based on total light absorption by the phytoplankton cells $\left[a_{\text {ph }}(\lambda)\right]$. The 'full' model results are compared with model variations: $(A)$ constant $a^{*}{ }_{p h}(\lambda) ;(B)$ constant $\hat{\varphi}_{\max , p h ;}(C)$ constant $\sigma \tau_{;}$and (D) constant $a^{*}{ }_{p h}(\lambda), \phi_{\max }$ ph and $\sigma \tau$

\section{Consequences of variability in model parameters}

It is possible with this data set to explore the sensitivity of model estimates to the observed variability in the phytoplankton physiology which is explicit in Eqs. (3) \& (4). This has been accomplished by comparison of model results derived using ecologically relevant variables [i.e. measured $E(\lambda, t)$ and chl] and different levels of parameter variability. Models 1 and 2 were applied for each day of the 2 cruises and at the 2 depths sampled. The models have the same mathematical formulation used to determine the P-I parameter values to avoid errors associated with inappropriate use of model parameters (see Frenette et al. 1993). The baseline or 'full' model, considered to provide the best estimate of actual in situ production, includes all parameters [e.g. $a_{\text {ph }}(\lambda), \phi_{\text {max ph }}$ and $\left.\sigma \tau\right]$ as measured for each station and sample depth. To evaluate the importance of the variability found in each of these parameters, constant values equal to the observed means were substituted into the formulation for 1 parameter at a time and also for all 3 at once. Production was evaluated at 1 min intervals and summed over the time from local apparent noon to sunset. The production estimates resulting from use of constant parameter values were then compared to the 'full' model calculations. The fully spectral models were used in all cases and all parameter variations were run with both Model 1 and Model 2 (Eqs. $3 \& 4$ ).
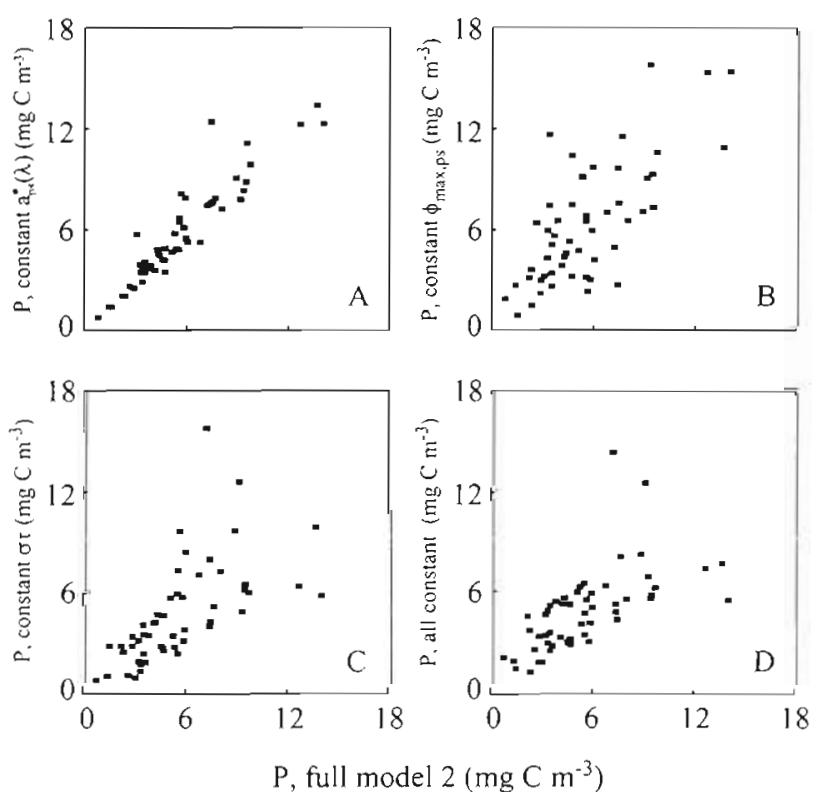

Fig. 5. Scatterplots as in Fig. 4, but using Model 2 (Eq. 4) which is based only on photosynthetically active light absorption by the phytoplakton cells $\left[a_{p s}(\lambda)\right\}$. The 'full' model results are compared with model variations: (A) constant $a_{p s}{ }_{p s}(\lambda)$; (B) constant $\phi_{\text {max.psi }}(C)$ constant $\sigma \tau$; and (D) constant $a_{p s}(\lambda)$, $\phi_{\max , p s}$ and $\sigma \tau$ 
Model calculations require specification of spectral irradiance as a function of time, $E(\lambda, t)$. $E(\lambda, t)$ between 400 and $700 \mathrm{~nm}$ was determined by interpolating the underwater $E_{\mathrm{d}}(\lambda)$ (measured near mid-day with the MER and specified in quantum-based units) to $1 \mathrm{~nm}$ resolution and normalizing the magnitude of these spectra so that the wavelength integral matched the continuously logged surface PAR values, adjusted for the fraction of surface PAR which penetrated to depth at the time of sampling, $T$ :

$$
E(\lambda, t)=E_{\mathrm{d}}(\lambda) \cdot \frac{T}{\int \operatorname{PAR}(t)}
$$

When combined with the $a^{*}{ }_{p h}(\lambda)$ measurements, this method allows the total light absorption to be specified accurately for any measured incident spectrum, thus avoiding biases associated with changes in the spectral properties of the phytoplankton or of the underwater light field (see Laws et al. 1990, Kyewalyanga et al. 1992). In all model cases, irradiance input was calculated in the same manner. No corrections were made for changes in $E_{\mathrm{d}}(\lambda)$ or $T$ which may occur with changes in sun angle over the day.

When the results of these model runs are presented as scatter plots (Figs. $4 \& 5$ ), the divergence from a $1: 1$ relationship between modeled values of production reflects the extent to which the calculations are sensitive to the observed parameter variability. As described in previous work using related models (Lewis et al. 1985,

Table 3. Summary of comparison between model results when parameters are held constant and 'full' model results, where all observed parameter variability is included. The parameter held constant in each case is indicated, with the corresponding residual mean square (RMS) in ( $\left.\mathrm{mg} \mathrm{C} \mathrm{m}^{-3}\right)^{2}$; each RMS value was determined relative to a 1:1 relationship with the 'full' model results. Significant differences in RMS values between model variations are based on F-tests, with the comparisons between Model 1 and Model 2 only tested for parallel parameters [e.g. constant $\alpha^{\circ}{ }_{\mathrm{ph}}(\lambda)$ vs constant $\left.a_{p s}{ }_{p s}(\lambda)\right]$. No correction was made for multiple testing, but all significant differences have $p<0.001$

\begin{tabular}{|c|c|c|c|}
\hline \multirow{2}{*}{$\begin{array}{l}\text { Model variation } \\
\text { Model } 1\end{array}$} & \multirow[t]{2}{*}{ RMS } & \multicolumn{2}{|c|}{ Significant differences } \\
\hline & & $\begin{array}{l}\text { Within Model } 1 \\
\text { variations }\end{array}$ & $\begin{array}{l}\text { With Model } 2 \\
\text { variations }\end{array}$ \\
\hline Constant $a^{*}{ }_{\mathrm{ph}}(\lambda)$ & 2.74 & $\begin{array}{l}\text { Constant } \phi_{\max , p h} \\
\text { Constant } \sigma \tau\end{array}$ & Constant $\alpha^{*}{ }_{p s}(\lambda)$ \\
\hline Constant $\phi_{\max , p h}$ & 9.16 & Constant $a^{\cdot}{ }_{p h}(\lambda)$ & None \\
\hline Constant $\sigma \tau$ & 7.38 & Constant $a_{p h}^{\prime}(\lambda)$ & None \\
\hline Model 2 & & $\begin{array}{l}\text { Within Model } 2 \\
\text { variations }\end{array}$ & $\begin{array}{l}\text { With Model } 1 \\
\text { variations }\end{array}$ \\
\hline Constant $\alpha_{p s}{ }_{p s}(\lambda)$ & 1.21 & $\begin{array}{l}\text { Constant } \phi_{\max , p s} \\
\text { Constant } \sigma \tau\end{array}$ & Constant $a_{p h}^{*}(\lambda)$ \\
\hline Constant $\phi_{\max , \mathrm{ps}}$ & 6.99 & Constant $a_{p s}^{*}(\lambda)$ & None \\
\hline Constant $\sigma \tau$ & 7.32 & Constant $a_{p s}(\lambda)$ & None \\
\hline
\end{tabular}
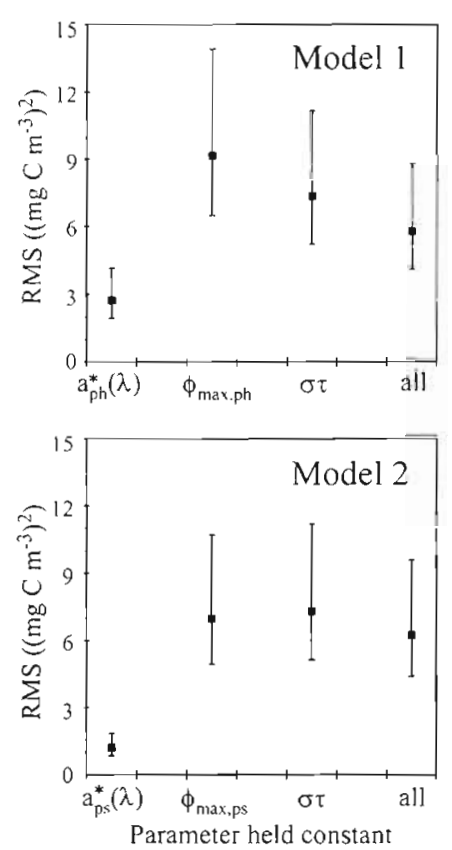

Fig. 6. Summary of residual mean square (RMS) values for the data shown in Figs. 4 \& 5. RMS values were calculated relative to a 1:1 relationship with the 'full' model results and indicated $95 \%$ confidence intervals were calculated from the $\chi^{2}$ distribution. (A) RMS values for Model 1 variations; and (B) RMS values for Model 2 variations

Babin et al. 1993), production estimates depend on the value of the pigment-specific absorption coefficient (Figs. 4A \& 5A). It is apparent from these results, however, that accurate assessment of $\phi_{\max , p h}$ (or $\phi_{\max , p s}$ ) and $\sigma \tau$ is of even greater importance in modeling of spatially resolved primary production (Figs. 4B, C \& 5B, C). To summarize these results, the mean square errors relative to a $1: 1$ relationship with the 'full' model estimates were calculated (Fig. 6, Table 3). For both Model 1 and Model 2, the variance due to inadequately representing variability in $\phi_{\max }$ and $\sigma \tau$ is significantly greater than that due to modeling with constant $a^{*} \mathrm{ph}(\lambda)$ [or $a^{*}{ }_{p s}(\lambda)$ ] (Table $3 ; p<0.001$ ). As expected based on the lower variability in $\alpha^{\circ}{ }_{p s}(\lambda)$ relative to $\alpha^{*}{ }_{\mathrm{ph}}(\lambda)$ (Sosik \& Mitchell 1995), Model 2 estimates are significantly less sensitive to the observed variability in $a^{*}{ }_{p s}(\lambda)$ than Model 1 is to $a^{\circ}{ }_{p h}(\lambda)$ (Table 3; p<0.001). While, as predicted by Sosik \& Mitchell (1995), the variance due to constant $\phi_{\max , p s}$ is less than that resulting from constant $\phi_{\max , p h}$ the difference is not significant. These results suggest that adequately parameterizing variability in $\phi_{\max , p h}, \phi_{\max , p s}$ and $\sigma \tau$ is of 

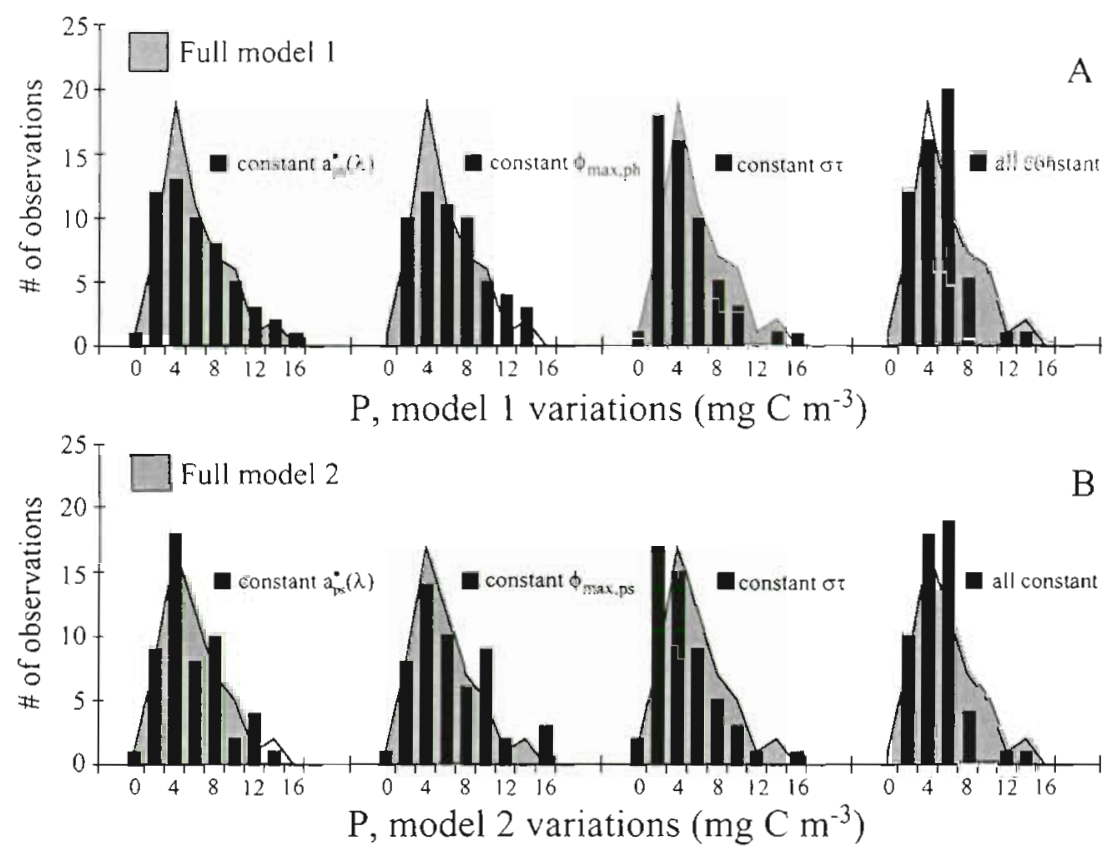

Fig. 7. Frequency distributions of modeled primary production values for the same model variations compared in Figs. 4 \& 5. Distribution of estimates derived from the 'full' model results were calculated with the same bin size as the other distributions and are presented as continuous functions only for clarity. In each case, the mean primary production is not more than $15 \%$ different from the mean of the 'full' model estimates. (A) Results for Model 1; (B) results for Model 2 greater significance than $a^{*}{ }_{p h}(\lambda)$ or $a_{p s}(\lambda)$, but it should be emphasized that, aside from pump-and-probe type fluorescence techniques, current methods to assess $\phi_{\max }$ require characterization of the absorption properties of the phytoplankton.

The results of this modeling exercise can provide some insight into consequences of observed parameter variability for estimation of primary production at larger spatial scales. From frequency distributions of time-integrated primary production for each of the model runs, it is evident that use of average parameter values does not introduce large biases in the distribution of values calculated for the large area and 2 relative light levels sampled in this study (Fig. 7). This result might not be expected if, for instance, sites of highest productivity were always associated with parameter values consistently higher or lower than the means. For all parameter variations considered, the largest difference in the mean production from the 'full' model mean is $15 \%$. While it is difficult to infer implications for vertically integrated and areally integrated production estinates from only 2 sample depths, these results suggest that characterization of the average photophysiological parameters for a region and time, based on a relatively small sampling, may be adequate for deriving model estimates of primary production at the regional scale. A more robust. test of this hypothesis requires a comparison to actual in situ primary production measurements with greater vertical resolution and also investigation of the effects of temporal variability in parameter values.

This study documents that the physiological parameters of many bio-optical models for primary production are highly variable for natural assemblages of phytoplankton in the California Current System, even during a period of relatively low physical forcing. The observed variability has important consequences for adequate modeling of primary production at high spatial and temporal resolution. While larger scale estimates of reasonable accuracy may be achievable with the use of constant parameter values, it is important to recognize that these values themselves must be representative. For this data set, the mean parameter values differ markedly from published estimates based on laboratory culture work (e.g. Kiefer \& Mitchell 1983, Sakshaug et al. 1989). Despite the generally good agreement found in some cases (Marra et al. 1992, 1993), these results suggest that application of laboratory-based parameter values directly to field situations should be exercised with caution. Some of the discrepancy between laboratory and field results may be due to lack of accurate parameter determination (e.g. neither Kiefer \& Mitchell 1983 nor Sakshaug et al. 1989 measured absorption spectra). In addition, however, there are probably important differences between the optical and photosynthetic physiology of commonly studied laboratory cultures and natural phytoplankton assemblages.

Acknowledgements. This work would not have been possible without the cooperation of the many people involved in the CalCOFI and FORAGE programs. I owe them for assistance at sea and with data processing and for freely providing hydrographic and chemical data. I especially thank Eric Brody for technical help at sea. Greg Adelman of Bıospherical Instruments provided the calibration correction necessary to accurately use the QSL-100 sensor to determine PAR levels in the blue light $P-I$ incubator. Ron Lynn and Arnold Mantyla graclously provided contours of hydrographic properties. I also 
thank sincerely Tom Hayward and Greg Mitchell who contributed valuable discussion and criticism of the work and manuscript. Three anonymous reviewers also provided useful comments and suggestions. This work was supported by ONR contract N00014-91-J-1186 and NASA grant NAGW-3665 to B. G. Mitchell and a NASA Graduate Student Researchers Program Fellowship and a DOE Global Change Distinguished Postdoctoral Fellowship to H.M.S. Woods Hole Oceanographıc Institution contributıon \#9344

\section{LITERATURE CITED}

Babin M, Therriault JC., Legendre L, Condal A (1993) Variations in the specific absorption coefficient for natural phytoplankton assemblages: impact on estimates of primary production. Limnol Oceanogr 38:154-177

Babin M, Therriault JC, Legendre L, Nieke B, Reuter R, Condal A (1995) Relationship between maximum quantum yield of carbon fixation and the minimum quantum yield of chlorophyl] a in vivo fluorescence in the Gulf of St. Lawrence. Limnol Oceanogr 40:956-968

Balch WM, Eppley RW, Abbott MR (1989) Remote sensing of primary production. II. A semi-analytical algorithm based on pigments, temperature and light. Deep Sea Res 36 1201-1217

Bidigare RR, Ondrusek ME, Morrow JH, Kiefer D (1990) In vivo absorption properties of algal pigments. Ocean Optics X SPIE 1302:290-302.

Bidigare RR, Prézelin BB, Smith RC (1992) Bio optıcal models and the problems of scaling. In: Falkowski PG, Woodhead AD (eds) Primary productivity and biogeochemical cycles in the sea. Plenum, New York, p 175-212

Bidigare RR, Schofield O, Prézelin BB (1989) Influence of zeaxanthin on quantum yield of photosynthesis of Synechococcus clone WH7803. Mar Ecol Prog Ser 56:177-188

Bidigare RR, Smith RC, Baker KS, Marra J (1987) Oceanic primary production estimates from measurements of spectral irradiance and pigment concentrations. Global Biogeochem Cycles 1:171-186

Bricaud A, Babin M, Morel A, Claustre H (1995) Variability in the chlorophyll-specufic absorption coefficients of natural phytoplankton: analysis and parameterization. J Geophys Res 100:13321-13332

Carder KL, Lee ZP, Marra J, Steward RG, Perry MJ (1995) Calculated quantum yield of photosynthesis of phytoplankton in the Marine Light-Mixed Layers $\left(59^{\circ} \mathrm{N}, 21^{\circ} \mathrm{W}\right)$. J Geophys Res 100:6655-6663

Chalup MS, Laws EA (1990) A test of the assumptions and predictions of recent microalgal growth models using the marine phytoplankton Pavlova lutheri. Limnol Oceanogr 35:583-596

Cleveland JS, Perry MJ (1987) Quantum yield, relative specific absorption and fluorescence in nitrogen-limited Chaetoceros gracilis. Mar Biol 94:489-497

Cleveland JS, Perry MJ, Kiefer DA, Talbot MC (1989) Maximal quantum yield of photosynthesis in the northwestern Sargasso Sea. J Mar Res 47:869-892

Cullen JJ (1990) On models of growth and photosynthesis in phytoplankton. Deep Sea Res 37:667-683

Cullen JJ, Lewis MR, Davis CO, Barber RT (1992) Photosynthetic characteristics and estimated growth rates indicate grazing is the proximate control of primary production in the equatorial Pacific. J Geophys Res 97:639-654

Dickey TD (1988) Recent advances and future directions in multidisciplinary in situ oceanographic measurement systems. In: Rothschild BJ (ed) Toward a theory on biological- physical interactions in the world ocean. NATO ASI Series, series C, no. 239. Kluwer Academic Publishers, Dordrecht, p 555-598

Dubinsky Z, Berman T (1976) Light utilization efficiencies of phytoplankton in Lake Kinneret (Sea of Galilee). Limnol Oceanogr 21-226-230

Dubinsky Z, Falkowski PG, Wyman K (1986) Light harvesting and utilization by phytoplankton. Plant Cell Physiol 27 $1335-1349$

Eppley RW, Stewart E, Abbott MR, Heyman U (1985) Estimating ocean primary production from satellite chlorophyll Introduction to regional differences and statistics for the Southern California Bight. J Plankton Res 7:57-70

Falkowski PG (1992) Molecular ecology of phytoplankton photosynthesis. In: Falkowski PG, Woodhead AD (eds) Primary productivity and biogeochemical cycles in the sea. Plenum, New York, p 47-67

Falkowski PG, Dubinsky Z, Wyman K (1985) Growth-irradiance relationships in phytoplankton. Limnol Oceanogr 30 $311-321$

Falkowski PG, Owens TG, Ley A, Mauzerall D (1981) Effects of growth irradiance levels on the ratio of reaction centers in two species of marine phytoplankton. Plant Physiol 68:969-973

Frenette JJ, Demers S, Legendre L, Dodson J (1993) Lack of agreement among models for estimating the photosynthetic parameters. Limnol Oceanogr 38:679-687

Greene RM, Geider RJ, Falkowski PG (1991) Effect of iron limitation on photosynthesis in a marine diatom. Limnol Oceanogr 36:1772-1782

Harding LW Jr, Prézelin BB, Sweeney BM, Cox JL (1982) Primary production as influenced by diel periodicity of phytoplankton photosynthesis. Mar Biol 67:179-186

Harrison WG, Platt T (1986) Photosynthesis-irradiance relationships in polar and temperate phytoplankton populations. Polar Biol 5: 153-164

Hayward TL (1993) Preliminary observations of the 1991-1992 El Niño in the California Current. CalCOFI Rep 34:21-29

Herzig R, Falkowski PG (1989) Nitrogen limitation in Isochrysis galbana (Haptophyceae). I. Photosynthetic energy conversion and growth efficiency. J Phycol 25:462-471

Hoepffner N, Sathyendranath S (1992) Bio-optical characteristics of coastal waters: absorption spectra of phytoplankton and pigment distribution in the western North Atlantic. Limnol Oceanogr 37:1660-1679

Hood RR, Abbott MR, Huyer A (1991) Phytoplankton and photosynthetic light response in the coastal transition zone off northern California in June 1987. J Geophys Res 96 $14769-14780$

Jenkin PM (1937) Oxygen production by the diatom Coscinodiscus excentricus Ehr. in relation to submarne illumination in the English Channel. J Mar Biol Ass UK 22:301-343

Johnsen G, Sakshaug E (1993) Bio-optical characteristics and photoadaptive responses in the toxic and bloom-forming dinoflagellates Gyrodinium aureolum, Gymnodinium galatheanum, and two strains of Prorocentrum minimum. J Phycol 29:627-642

Kiefer DA, Mitchell BG (1983) A simple steady state description of phytoplankton growth based on absorption cross section and quantum efficiency. Limnol Oceanogr 28:770-776

Kishino M, Okami N, Takahashi M, Ichimura S (1986) Light utilization efficiency and quantum yield of phytoplankton in a thermally stratified sea. Limnol Oceanogr 31:557-566

Kishino M, Takahashi N, Okami N, Ichimura S (1985) Estimation of the spectral absorption coefficients of phytoplankton in the sea. Bull Mar Sci 37:634-642

Kolber Z, Wyman K, Falkowski PG (1990) Natural variability in photosynthetic energy conversion efficiency: a field 
study in the Gulf of Maine. Lımnol Oceanogr 35:72-79

Kolber Z. Zehr J, Falkowski PG (1988) Effects of growth irradiance and nitrogen limitation on photosynthetic energy conversion in photosystem II. Plant Physiol 88:923-929

Kyewalyanga M, Platt T, Sathyendranath S (1992) Ocean primary production calculated by spectral and broad-band models. Mar Ecol Prog Ser 85:171-185

Laws EA, DiTullio GR, Carder K, Betzer PR, Hawes S (1990) Pri-mary production in the deep blue sea. Deep Sea Res 37:715-730

Levasseur ME, Morissette JC, Popovic R, Harrison PJ (1990) Effects of long term exposure to low temperature on the photosynthetic apparatus of Dunaliella tertiolecta (Chlorophyceae). J Phycol 26:479-484

Lewis MR, Smith JC (1983) A small volume, short-incubationtime method for measurement of photosynthesis as a function of incident irradiance. Mar Ecol Prog Ser 13:99-102

Lewis MR, Warnock RE, Platt T (1985) Absorption and photosynthetic action spectra for natural phytoplankton populations: implications for production in the open ocean. Limnol Oceanogr 30:794-806

Ley AC, Mauzerall DC (1982) Absolute absorption cross-sections for photosystem II and the minimum quantum requirement for photosynthesis in Chlorella vulgaris. Biochim Biophys Acta 680:95-106

Marra J, Chamberlin WS, Knudson C (1993) Proportionality between in situ carbon assimilation and bio-optical measures of primary production in the Gulf of Maine in summer. Limnol Oceanogr 38:232-238

Marra J, Dickey T, Chamberlin WS, Ho C, Granata T, Kiefer DA, Langdon $C$, Smith R, Baker K, Bidigare R, Hamilton M (1992) Estimation of seasonal primary production from moored optical sensors in the Sargasso Sea. J Geophys Res 97:7399-7412

Mitchell BG (1987) Ecological implications of variability in marine particulate absorption and fluorescence excitation spectra. PhD dissertation. The University of Southern California, Los Angeles

Mitchell BG (1990) Algorithms for determining the absorption coefficient of aquatic particulates using the quantitative filter technique (QFT). Ocean Optics X SPIE 1302:137-148

Mitchell BG, Holm-Hansen O (1991) Bio-optical properties of Antarctic Peninsula waters: differentiation from temperate ocean models. Deep Sea Res 38:1009-1028

Mitchell BG, Kiefer DA (1988) Chlorophyl a specific absorption and fluorescence excitation spectra for light-limited phytoplankton. Deep Sea Res 35:63.9-663

Morel A (1978) Available, usable, and stored radiant energy in relation to marine photosynthesis. Deep Sea Res 25:673-688

Morel A (1991) Light and marine photosynthesis: a spectral model with geochemical and climatological implications. Prog Oceanogr 26:263-306

Morel A, Lazzara L, Gostan J (1987) Growth rate and quantum yield time response for a diatom to changing urradiances (energy and color). Limnol Oceanogr 32:1066-1084

Myers J, Graham JR (1971) The photosynthetic unit in Chlorella measured by repetitive short flashes. Plant Physiol. 48:282-286

Neori A, Vernet M, Holm-Hansen O, Haxo FT (1986) Relationship between action spectra for chlorophyll a fluorescence and photosynthetic $\mathrm{O}_{2}$ evolution in algae. J Plankton Res 8:537-548

Neori A, Vernet M, Holm-Hansen O, Haxo FT (1988) Comparison of chlorophyll far-red and red fluorescence excita. tion spectra with photosynthetic oxygen action spectra for photosystem II in algae. Mar Ecol Prog Ser 44:297-302

Partensky F, Hoepffner N, Li WKW, Ulloa O, Vaulot D (1993)
Photoacclimation of Prochlorococcus sp. (Prochlorophyta) strains isolated from the North Atlantic and the Mediterranean Sea. Plant Physiol 101:285-296

Platt T, Jassby AD (1976) The relationship between photosynthesis and light for natural assemblages of coastal marme phytoplankton. J Phycol 12:421-430

Platt T, Sathyendranath S (1988) Oceanic primary production estimation by remote sensing at local and regional scales. Science 241:1613-1620

Platt $T$, Sathyendranath S, Ulloa O, Harrison WG, Hoepffner $N$, Goes J (1992) Nutrient control of phytoplankton photosynthesis in the Western North Atlantic. Nature 356:229-231

Prézelin BB, Bidigare RR, Matlick HA, Putt M, Ver Hoven B (1987) Diurnal patterns of size-fractionated primary productivity across a coastal front. Mar Biol 96:563-574

Ryther JH, Menzel DW (1959) Light adaptation by marine phytoplankton. Limnol Oceanogr 4:492-497

Ryther JH, Yentsch CS (1957) The estimation of phytoplankton production in the ocean from chlorophyll and light data. Limnol Oceanogr 2:281-286

Sakshaug E, Andresen K, Kiefer DA (1989) A steady state description of growth and light absorption in the marine planktonic diatom Skeletonema costatum. Limnol Oceanogr 34:198-205

Sakshaug E, Johnsen G. Andresen K, Vernet M (1991) Modeling of light-dependent algal photosynthesis and growth: experiments with the Barents Sea diatoms Thalassiosira nordenskioeldii and Chaetoceros furcellatus. Deep Sea Res 38:415-430

Sathyendranath $S$, Platt $T$, Caverhill CM, Warnock RE, Lewis MR (1989) Remote sensing of oceanic primary production: computations using a spectral model. Deep Sea Res 36: $431-453$

Schofield O, Bidigare RR, Prézelın BB (1990) Spectral photosynthesis, quantum yield and blue-green light enhancement of productivity rates in the diatom Chaetoceros gracile and the prymnesiophyte Emiliania huxleyi. Mar Ecol Prog Ser 64:175-186

Schofield O, Prézelin BB, Bidigare RR, Smith RC (1993) In situ photosynthetic quantum yield. Correspondence to hydrographic and optical variability in the Southern California Bight. Mar Ecol Prog Ser 93:25-37

Schofield O, Prézelin BB, Smith RC, Stegmann PM, Nelson. NB, Lewis MR, Baker KS (1991) Variability in spectral and nonspectral measurements of photosynthetic light utilization efficiencies. Mar Ecol Prog Ser 78:253-271

Scripps Institution of Oceanography (1992) Physical, chemical and biological data, CalCOFI cruises 9202 and 9204 . S1O Ref. 92-20, University of California, San Diego

Smith RC, Bıdigare RR, Prézelin BB, Baker KS, Brooks JM (1987) Optical characterization of primary productivity across a coastal front. Mar Biol 96:575-591

Sosik HM, Mitchell BG (1991) Absorption, fluorescence and quantum yield for growth in nitrogen limited Dunaliella tertiolecta. Limnol Oceanogr 36:910-921

Sosik HM, Mitchell BG (1994) The effects of temperature on growth, light absorption, and quantum yield in Dunaliella tertiolecta (Chlorophyceae). J Phycol 30:833-840

Sosik HM, Mitchell BG (1995) Absorption by phytoplankton photosynthetic pigments, and detritus in the California Current System. Deep Sea Res 42:1717-1748

Webb WL, Newton M, Starr D (1974) Carbon dioxide exchange of Alnus rubra: a mathematical model. Oecologia 17 $281-291$

Welschmeyer NA, Lorenzen CJ (1981) Chlorophyll-specific photosynthesis and quantum efficiency at subsaturating light intensities. J Phycol 17:283-293 